Revta brasil. Bot., São Paulo, V.24, n.2, p.205-211, jun. 2001

\title{
Biologia floral e sistema de reprodução de Merostachys riedeliana (Poaceae: Bambusoideae)
}

\author{
FREDERICO AUGUSTO G. GUILHERME ${ }^{1,2}$ e KAILA RESSEL ${ }^{1}$
}

(recebido: 1 de março de 2000; aceito: 7 de março de 2001)

\begin{abstract}
Floral biology and breeding system of Merostachys riedeliana (Poaceae: Bambusoideae)). Merostachys riedeliana Rupr. is a long-lived monocarp species common in the understorey of tropical semideciduous forest fragments in the south of Minas Gerais, Brazil. Its floral biology and breeding system were studied and compared with others bamboos. Due to its rhizome, it occurs in clumps and has a remarkable capacity for vegetative multiplication, which ceases a few months before the emergence of the first inflorescences. The beginning of the flowering and the death of the entire population occurred respectively on October 1998 and May 1999. The peak of the blooming episode took place during the hot and rainy months of the year (December and January). Each inflorescence produces in average 29 spikelets, which have hermaphrodite florets with three stamens and two plumose stigmas that are exposed during the anthesis. The abundant pollen is easily released by the wind or visitors. Apis mellifera $\mathrm{L}$. and Trigona spinipes $(\mathrm{F}$.) were the commonest visitors and behave as pollen thieves. These bees occasionally act as devices for dispersion of pollen, through vibration produced in the anthers. The excess of rain during flowering and the lack of wind in the understorey of the forest constrain the effectiveness of the anemophily. However, several morphological characters of the flowers, leaf fall and dense clumps tend to expect for wind pollination. Also, the auto-incompatibility index (0.99) showed that M. riedeliana is an autocompatible bamboo. So the auto-incompatibility does not favour the formation of fruits in vegetal clones, and the autocompatibility could result in the high production of seeds. Therefore the possible occurrence of clones of $M$. riedeliana in the forest fragments, due to the effective vegetative growth and the 30-32 years cyclic flowering intervals, might explain the high investment on spikelets production and autocompatible fruits formation.
\end{abstract}

RESUMO - (Biologia floral e sistema de reprodução de Merostachys riedeliana (Poaceae: Bambusoideae)). Merostachys riedeliana Rupr. é uma espécie monocárpica com floração cíclica e muito freqüente em sub-bosques de fragmentos florestais do sul do estado de Minas Gerais, Brasil. Sua biologia floral e seu sistema de reprodução foram estudados e comparados com os de outros bambus. Devido ao complexo sistema de rizomas, formam touceiras vigorosas no interior da floresta, ocorrendo a interrupção na produção de novos colmos meses antes do aparecimento das primeiras inflorescências. O início da floração maciça e da morte da população ocorreu em outubro de 1998 e maio de 1999, respectivamente, com pico de floração durante a estação quente e chuvosa (dezembro e janeiro). As inflorescências espiciformes possuem, em média, 29 espiguetas. Estas são hermafroditas com três anteras poricidas e dois estigmas plumosos que se expõem durante a antese. O pólen é abundante e facilmente liberado das anteras pelo vento ou pelos visitantes. Apis mellifera L. e Trigona spinipes (F.) foram os visitantes mais freqüentes, atuando como pilhadores de pólen e, ocasionalmente, através de movimentos vibratórios, como elementos auxiliares para a dispersão do pólen. A alta pluviosidade durante a floração e a escassez de vento no sub-bosque da floresta, podem diminuir a efetividade da anemofilia. No entanto, vários caracteres morfológicos das espiguetas, queda de folhas e o hábito espacialmente agrupado, apontam para uma polinização pelo vento. Testes de polinização controlada, mostraram que $M$. riedeliana é autocompatível (ISI 0,99). A auto-incompatibilidade não favorece a formação de frutos em clones vegetais, ao passo que a autocompatibilidade poderia resultar em uma elevada produção de sementes. Assim, a possível ocorrência de clones de M. riedeliana nos fragmentos florestais, originados pelo crescimento vegetativo durante os intervalos reprodutivos de 30-32 anos, poderiam explicar o alto investimento na produção de espiguetas e a formação de frutos provenientes da autocompatibilidade.

Key words - Semideciduous tropical forest, wind pollination, autocompatibility, vegetative growth, Merostachys

\section{Introdução}

Os bambus lenhosos estão entre as gramíneas morfologicamente mais complexas, especialmente em relação às estruturas vegetativas (Soderstrom $e t$ al. 1988, Londoño 1990), compreendendo o maior e mais bem sucedido grupo de gramíneas encontrado

1. UNESP, Departamento de Botânica, Av. 24-A, 1515, Caixa Postal 199, 13506-900 Rio Claro, SP, Brasil.

2. Autor para correspondência: fagg@ @rc.unesp.br nas florestas tropicais (Soderstrom \& Calderón 1971, 1979, Sendulsky 1997). De maneira geral, apresentam florescimento monocárpico com intervalos que variam de 3 a 120 anos, com floração e frutificação maciças e eficiente sincronia (Janzen 1976, Nadgauda et al. 1990), mesmo quando amplamente distribuídos geograficamente (Liese 1987, Friar \& Kochert 1994). Esses períodos de frutificação intensa de espécies do gênero Merostachys, podem estar intimamente associados ao aumento de populações de algumas espécies de 
ratos em propriedades rurais (Pereira 1941, Giovannoni et al. 1946).

Devido aos longos intervalos reprodutivos, os estudos sobre as formas de reprodução e os mecanismos de polinização para bambus lenhosos são bastante escassos. Alguns poucos estudos dessa natureza foram realizados por Venkatesh (1984) e Nadgauda et al. (1993), que observaram duas espécies dicógamas e anemófilas e por Soderstrom \& Calderón (1971), que observaram uma espécie entomófila.

O gênero Merostachys, conhecido vulgarmente como taquara, distribui-se desde a América Central até a Argentina, com o centro de diversidade no Brasil (McClure 1973, Soderstrom et al. 1988, Sendulsky 1992, Watson \& Dallwitz 1994). Apresenta em torno de 20 espécies distribuídas ao longo do território nacional (McClure 1973, Filgueiras 1988), no entanto existe um grupo de aproximadamente 10 espécies que são difíceis de se distinguir umas das outras e que não podem ser agregadas sob um único nome (Sendulsky 1995). A espécie Merostachys riedeliana Rupr. é comumente encontrada em fragmentos florestais do sul do estado de Minas Gerais (Guilherme 1999) e é bastante usada para construção de forros e balaios em propriedades rurais.

Devido à efetiva ocupação do sub-bosque sob quaisquer condições de distúrbio, $M$. riedeliana pode alterar profundamente a fisionomia e a estrutura de florestas semidecíduas (Oliveira-Filho et al. 1994), podendo interferir de forma expressivamente negativa no recrutamento das espécies arbóreas (Guilherme 1999). Assim, este estudo teve como objetivos obter informações sobre os mecanismos de reprodução e a biologia floral de Merostachys riedeliana, esperando que os resultados possam auxiliar programas de manejo nos fragmentos florestais do sul do Estado de Minas Gerais.

\section{Material e métodos}

O estudo foi realizado entre abril de 1998 e maio de 1999 e foi desenvolvido em dois fragmentos florestais do sul do estado de Minas Gerais, localizados na Fazenda Patrimônio (21 ${ }^{\circ} 29^{\prime} \mathrm{S}$ e $44^{\circ} 22^{\prime}$ W) e no Parque Florestal Quedas do Rio Bonito $\left(21^{\circ} 19^{\prime} \mathrm{S}\right.$ e $44^{\circ} 59^{\prime}$ W), nos municípios de Madre de Deus de Minas e Lavras, respectivamente, que distam cerca de $110 \mathrm{~km}$. A região possui um clima do tipo Cwb, segundo a classificação de Köppen, com temperatura média anual de $19,6^{\circ} \mathrm{C}$ e mínimas atingindo em média $16,0{ }^{\circ} \mathrm{C}$, em julho e máximas de $21,8^{\circ} \mathrm{C}$, em janeiro. A precipitação média anual é de $1517 \mathrm{~mm}$, sendo que $93 \%$ das chuvas ocorrem entre outubro e abril (Oliveira-Filho et al. 1994).

Em ambas as áreas, foram observadas populações de Merostachys riedeliana em consideráveis densidades nos estratos médio e inferior da floresta semidecídua, marcando de forma expressiva esta fitofisionomia. Exsicatas da espécie estão depositadas nos herbários do Instituto de Botânica de São Paulo (SP) e da Universidade Federal de Lavras (ESAL) sob os números do coletor 171 e 178 (F.A.G. Guilherme).

Na Fazenda Patrimônio foram feitas, mensalmente, observações sobre o número de colmos $(\mathrm{n}=492)$ nas fenofases vegetativa, flor, fruto e morte. A fenofase considerada foi estabelecida quando em cada colmo marcado, predominava determinado estágio. Foram anotadas informações sobre o hábito da planta, a estrutura dos colmos e dos ramos reprodutivos e feitas as estimativas do investimento na produção de espiguetas e frutos em 1 ha. Para isto, usou-se como base de dados a contagem do número de colmos realizada em 0,97 ha (Guilherme 1999), além das médias de ramos com inflorescências em 10 colmos e a média de espiguetas em 295 inflorescências. No Parque Florestal foram realizados os tratamentos para avaliação do sistema reprodutivo.

Amostras de espiguetas e inflorescências foram fixadas em álcool $70 \%$, para caracterização morfológica e testes de microscopia de fluorescência na observação do crescimento de tubos polínicos (autopolinizações e polinizações cruzadas) 24, 48 e $72 \mathrm{~h}$ após a polinização, sendo que os pistilos foram submetidos à técnica de coloração de Martin (1959).

Para o estudo do sistema reprodutivo, foram realizados quatro tratamentos, sendo que todas as espiguetas das 49 inflorescências utilizadas foram avaliadas: 1- espiguetas não emasculadas, ensacadas com papel impermeável, as quais foram polinizadas manualmente após a antese, utilizando-se pólen de outras flores da mesma inflorescência (autopolinização); 2espiguetas emasculadas, ensacadas com papel impermeável, as quais foram polinizadas manualmente após a antese, utilizando-se pólen de flores de outros colmos (polinização cruzada), encontrados a uma distância de aproximadamente $800 \mathrm{~m}$ do local experimental, para evitar a geitonogamia; 3- espiguetas emasculadas e ensacadas com papel impermeável sem polinização (agamospermia); 4- espiguetas marcadas e não ensacadas (desenvolvimento de frutos em condições naturais). A razão entre frutos formados por autopolinização (1) e polinização cruzada (2) definiu o índice de auto-incompatibilidade - ISI (sensu Bullock 1985).

Foram realizadas observações visuais diretas das 7:30 às 17:30 h, para verificar o comportamento dos insetos visitantes nas espiguetas de $M$. riedeliana, especialmente o modo e a freqüência das visitas. Alguns espécimes dos insetos foram capturados e fixados a seco e em álcool $70 \%$ para identificação.

\section{Resultados}

Os colmos de Merostachys riedeliana têm ápices pendentes e arqueados e possuem em média $2,3 \mathrm{~cm}$ de diâmetro $(\mathrm{DP}=0,6 ; \mathrm{n}=577)$ e $10,3 \mathrm{~m}$ de 
comprimento ( $\mathrm{DP}=3,6 ; \mathrm{n}=577)$. Formam touceiras robustas no interior da floresta, devido ao complexo sistema de desenvolvimento de rizomas do tipo paquimorfo. O período da floração foi antecedido de um aumento na queda de folhas e da interrupção na produção de colmos novos.

O desenvolvimento maciço das inflorescências iniciou-se em setembro de 1998 e as primeiras flores começaram a se abrir no mês de outubro, com um pico de floração em dezembro, prolongando-se até fevereiro de 1999 (figura 1). A maturação dos frutos e a morte dos colmos reprodutivos ocorreram de janeiro a abril e em maio do mesmo ano, respectivamente. $\mathrm{Na}$ Fazenda Patrimônio, no período de março de 1998, observaram-se alguns colmos no final do estágio reprodutivo, apresentando início de senescência. Por outro lado, no Parque Florestal, no mesmo período do ano seguinte, alguns colmos sequer apresentaram início de desenvolvimento das inflorescências, que só vieram a florescer no final do ano de 1999. Assim, a floração de $M$. riedeliana parece ocorrer ao longo de dois a três anos, sempre durante os meses mais quentes do ano (T. Sendulsky, dados não publicados).

Os ramos possuem em média $32,3 \mathrm{~cm}$ de comprimento ( $\mathrm{DP}=12,5 ; \mathrm{n}=253$ ) e se dispõem de forma verticilada logo acima do nó do colmo, terminando nas inflorescências. Estas são espiciformes e possuem espigas secundifloras, com desenvolvimento e maturação das flores ocorrendo do centro para as extremidades. Foram encontrados $69,8 \%$ dos ramos entre 1 e $5 \mathrm{~m}$ de altura aproximadamente, com média de 11 ramos por nó

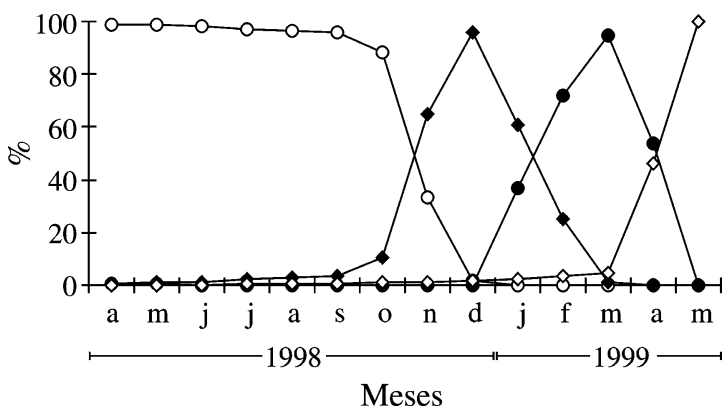

Figura 1. Fenograma de Merostachys riedeliana na Fazenda Patrimônio, Madre de Deus de Minas, durante o período de abril de 1998 a maio de 1999. Vegetativo (o); flor ( $\bullet$ ); fruto $(\bullet)$; morte $(\diamond)$.
( $\mathrm{DP}=8,1 ; \mathrm{n}=10)$. Uma média de 29 espiguetas esverdeadas e fusiformes, foram observadas por inflorescência ( $\mathrm{DP}=9,7 ; \mathrm{n}=295)$. Estas apresentaram, em média, 13,6 mm de comprimento ( $\mathrm{DP}=1,6 ; \mathrm{n}=30$ ) e flores hermafroditas. As duas glumas, o lema e a pálea, são verdes nas fases iniciais do florescimento, tornando-se castanhas ao longo do amadurecimento do fruto. Este é do tipo cariopse, seco e indeiscente, com média de $14,3 \mathrm{~mm}$ de comprimento ( $\mathrm{DP}=0,9 ; \mathrm{n}=30$ ).

Durante a abertura da flor, três longos estames de $14,8 \mathrm{~mm}$ de comprimento em média ( $\mathrm{DP}=1,2$; $\mathrm{n}=30$ ) ficam completamente expostos, com as anteras pendentes, sustentadas por delgados filetes. As anteras poricidas de $9 \mathrm{~mm}$ de comprimento em média ( $\mathrm{DP}=1 ; \mathrm{n}=30$ ), dispõem-se com os poros apicais direcionados para o chão, facilitando a obtenção do pólen pelos visitantes (figura 2). A tonalidade das anteras varia do verde ao preto, conforme os dias subseqüentes à abertura floral. Dois estigmas brancos e plumosos também se expõem simultaneamente às anteras, parecendo não haver dicogamia. Não foi sentido qualquer odor emitido pelas flores. As flores não produzem néctar, sendo o pólen o único recurso oferecido aos visitantes. O pólen, de coloração branca, pode ser liberado das anteras apenas com a movimentação

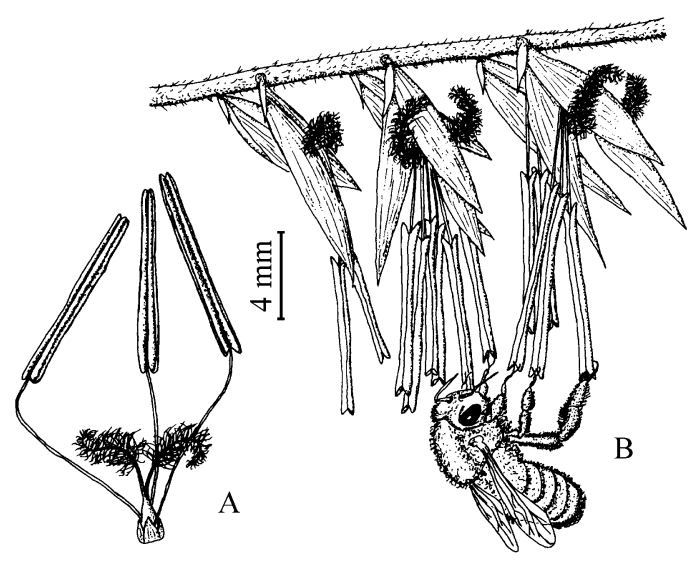

Figura 2. Detalhes da flor e visita de abelha em Merostachys riedeliana. A. Estruturas reprodutivas da flor, mostrando o gineceu com os dois estigmas plumosos e os três estames com os delgados filetes saindo da base do ovário, envolvida por três lodículas. B. Parte da inflorescência mostrando a visita de Apis mellifera (notar que o inseto pousa nas anteras e não tem contato com o estigma das flores). 
dos ramos, que é proporcionada pelas correntes de ar.

A abertura das flores não foi observada, mas possivelmente ocorre pela manhã, quando as espiguetas são intensamente visitadas por abelhas. Apis mellifera L. e Trigona spinipes (F.) (Hymenoptera) foram as espécies mais freqüentes, estando presentes durante todo o período de observações e em todos os horários avaliados, mesmo nos dias mais frios e nublados com alguma precipitação. Em todas as ocasiões, ambas as espécies de abelha apresentaram pólen no terceiro par de pernas. As duas espécies mostraram comportamento similar, agarrando-se em várias anteras de uma ou mais flores concomitantemente e realizando um movimento vibratório, promovendo a liberação do pólen. Em seguida, as abelhas voavam para outras inflorescências próximas. Não houve contato com os estigmas das flores durante as visitas dos insetos (figura 2). Indivíduos de duas espécies de dípteros e um pequeno coleóptero (Chrysomelidae), visitantes pouco freqüentes, foram observados alimentando-se de pólen retirado diretamente das anteras. Ambos os dípteros pousavam e se locomoviam nas espiguetas, entrando em contato com a região estigmática com o abdômen ou as pernas, talvez, ocasionalmente, atuando como polinizadores.

Com exceção do teste para observar agamospermia, constatou-se a formação de frutos de M. riedeliana em todos os tratamentos, com maturação ocorrendo cerca de 45 dias após a polinização (tabela 1). O índice de auto-incompatibilidade (ISI) de 0,99 indica que a espécie é autocompatível. Em condições naturais (controle), a formação de frutos foi mais alta, indicando que os testes de polinizações manuais podem ter interferido mecanicamente na eficiência

Tabela 1. Porcentagem de frutos formados nos tratamentos para o estudo do sistema de reprodução em Merostachys riedeliana. (NI = número de inflorescências utilizadas por tratamento, $\overline{\mathrm{X}}=$ média de frutos formados por inflorescência).

\begin{tabular}{lrrrrc}
\hline Tratamentos & flores & frutos & $\%$ & NI & $\bar{X}$ \\
\hline Autopolinização & 210 & 44 & 20,9 & 7 & 19,9 \\
Polinização cruzada & 160 & 34 & 21,2 & 7 & 19,7 \\
Agamospermia & 77 & 0 & 0 & 5 & 0 \\
Controle & 817 & 434 & 53,1 & 30 & 52,1 \\
\hline
\end{tabular}

do processo. Além disso, no período de estudo, as chuvas na região foram muito intensas e as inflorescências ensacadas com papel impermeável tiveram uma alta infestação por fungos, o que também pode ter afetado a formação de frutos. Observações em microscopia de fluorescência mostraram germinação e crescimento de tubos polínicos em pistilos autopolinizados e de polinização cruzada. Até $72 \mathrm{~h}$ estes tubos não chegavam à base do estilete em nenhum dos tratamentos.

Como foram registrados em média 9785 espiguetas por colmo (DP $=1015 ; \mathrm{n}=10)$ e 7105 colmos por ha, estimou-se a ocorrência de um total de aproximadamente 70 milhões de espiguetas por ha. Considerando a porcentagem de frutos formados no tratamento controle e que o peso médio de 100 frutos foi de $3,65 \mathrm{~g}(\mathrm{DP}=0,1 ; \mathrm{n}=16)$, obteve-se uma produção de 1,35 toneladas de frutos por ha e em torno de 3375 sementes por $\mathrm{m}^{2}$.

\section{Discussão}

Os ciclos de floração e frutificação de Merostachys riedeliana deste estudo concordam com os relatos de T. Sendulsky (dados não publicados), em que coletas botânicas da espécie em estado fértil, foram realizadas nos anos de 1834, $1899,1930,1965-67$ e 1998-99. Em torno do ano de 1866, é possível que tenha ocorrido outra floração, no entanto, sem registros de material botânico. Sendo assim, é provável que os intervalos reprodutivos sejam de 30 a 32 anos, esperando-se uma próxima floração em torno do ano de 2030. A época do ano em que essas coletas foram realizadas, também são condizentes com o atual estudo, correspondendo sempre aos períodos mais quentes do ano.

A interrupção na produção de novos colmos, meses antes da floração gregária, pode estar associada ao armazenamento de energia em benefício da floração e a subsequiente e abundante frutificação, as quais podem consumir as reservas energéticas das células parenquimáticas dos colmos e rizomas (Liese 1987). A ausência de novos colmos pode ser um bom indicador do início da floração (Calderón \& Soderstrom 1980, Pohl 1991). 
Em relação aos visitantes florais, mesmo com uma elevada frequiência de visitas de abelhas às flores de $M$. riedeliana, a melitofilia não parece ser importante para a formação de frutos. Claramente, Apis mellifera e Trigona spinipes pousavam apenas nas anteras, realizando a extração do pólen através de movimentos vibráteis. Entretanto, devido ao direcionamento da abertura das anteras, esses insetos atuariam como importantes agentes auxiliares para a liberação e dispersão do pólen pelas correntes de ar, e conseqüentemente estariam contribuindo para a polinização pelo vento. Outras duas espécies de bambus estudadas por Nadgauda et al. (1993) (Dendrocalamus strictus Nees) e Venkatesh (1984) (Ochlandra travancorica (Bedd.) Benth. ex Gamble) são tipicamente anemófilas, mesmo que visitadas por A. mellifera. Venkatesh (1984) e Nadgauda et al. (1993) não consideram que esta abelha seja uma polinizadora efetiva, já que ela ignora as flores no período em que elas se encontram apenas com o estigma receptivo. Em relação aos outros visitantes florais de Merostachys, é possível que dípteros atuem acidentalmente como polinizadores, devido à baixa frequiência de visitas às flores.

O pólen é um recurso alimentar para muitos insetos, os quais podem atuar como agentes polinizadores (Faegri \& Van der Pijl 1979). Filgueiras \& Pereira (1988) observaram que as flores de Actinocladum verticillatum (Nees) McClure ex Soderstrom, um bambu típico de cerrado, foram visitadas por muitos insetos, principalmente abelhas do gênero Trigona. Entretanto, na maioria das vezes, a polinização em gramíneas é, de fato, efetuada pelo vento (Bogdan 1960, Whitehead 1969, Soderstrom \& Calderón 1971, Connor 1986).

Dos poucos estudos relacionados com polinização em Bambusoideae, existem tanto espécies anemófilas, tais como Ochlandra travancorica (Venkatesh 1984), Dendrocalamus strictus (Nadgauda et al. 1993) e Chusquea cf. meyeriana (Olmos 1996), quanto entomófilas, como o gênero Pariana (Soderstrom \& Calderón 1971). No entanto, em estratos inferiores de florestas, o vento é tão escasso e infreqüente, que a anemofilia é dificultada (Whitehead 1969, Faegri \& Van der Pijl 1979). Apesar de $M$. riedeliana ocorrer em sub-bosque de fragmentos florestais e florescer em épocas de chuvas intensas, ela é uma espécie, provavelmente, anemófila. As características morfológicas adaptativas de suas espiguetas, tais como redução ou ausência do perianto, ausência de nectários, de cor ou de odores perceptíveis, inflorescências com muitas flores, anteras grandes e abundância de pequenos grãos de pólen, estigma plumoso e número reduzido de óvulos na flor, são características da síndrome de anemofilia (Soderstrom \& Calderón 1971, Faegri \& Van der Pijl 1979).

Corroborando essa síndrome, em muitas espécies anemófilas houve uma redução do número de óvulos por flor; assim apenas um ou poucos grãos de pólen são necessários para realizar a fertilização em uma dada flor (Whitehead 1969). Além disso, a efetividade do estigma plumoso de $M$. riedeliana na captação do pólen é aumentada pela sua exposição para fora da espigueta. As anteras também são expostas através de longos filetes, facilitando a disseminação do pólen pelo vento.

Devido à velocidade do vento, menor dentro de uma floresta do que em áreas abertas, boa parte das angiospermas polinizadas pelo vento florescem antes do brotamento de novas folhas na comunidade florestal (Whitehead 1969). No caso de $M$. riedeliana, o fato da queda das folhas ocorrer no mesmo período do desenvolvimento das inflorescências pode favorecer a anemofilia. De fato, muitos bambus perdem todas as suas folhas no pico da floração (Calderón \& Soderstrom 1980), por exemplo Guadua amplexifolia Presl (Kennard 1955) e Actinocladum verticillatum (Soderstrom 1981).

As razões para a evolução da polinização pelo vento em espécies de sub-bosque de florestas tropicais são obscuras (Bawa \& Crisp 1980). Levando-se em consideração o ciclo reprodutivo extenso e o eficiente investimento no crescimento vegetativo de $M$. riedeliana, pode-se sugerir uma baixa pressão seletiva para evolução da síndrome de polinização biótica. Várias espécies de bambus lenhosos possuem longos intervalos reprodutivos, sendo pouco dependentes da reprodução sexual, apresentando um complexo sistema de rizomas, o que lhes permite ocupar vastas áreas (Pohl 1991).

A ocupação intensa de $M$. riedeliana no sub-bosque florestal, formando densos agrupamentos, proporciona uma forte supressão da 
regeneração natural de espécies arbóreas (Oliveira-Filho et al. 1994, Carvalho 1997, Guilherme 1999). Assim sendo, a barreira física que seria imposta por parte de árvores e arbustos regenerantes se torna reduzida, proporcionando condição favorável ao fluxo do pólen através das correntes de ar.

A polinização pelo vento em bambus não está associada a mecanismos de auto-incompatibilidade (Janzen 1976). Uma explicação para isto seria a baixa precisão da anemofilia devido à rápida acomodação do pólen, necessitando de populações com hábitos agrupados e uma grande incidência de pólen próximo do recurso de origem para um maior sucesso na fecundação (Whitehead 1969, Faegri \& Van der Pijl 1979). Além disso, os bambus possuem multiplicação vegetativa através de rizomas, possibilitando que clones ocupem extensas áreas (Connor 1986).

Devido à floração cíclica e à natureza monocárpica dos bambus, a auto-incompatibilidade poderia restringir severamente a formação de frutos se apenas um clone estivesse presente em determinado local (Richards 1986). Por outro lado, a autocompatibilidade proporcionaria uma maior produção de frutos, uma vez que aumentaria as chances de sucesso na polinização (Bawa 1974). No atual estudo, observou-se um investimento maciço na floração, sendo que mais da metade das flores (53\%) produziram frutos (tratamento controle).

Os resultados dos testes de polinização controlada indicam a existência de autocompatibilidade em $M$. riedeliana. Os intervalos reprodutivos variando de 30 a 32 anos e a eficaz propagação vegetativa, resultando em densos agrupamentos, possivelmente com um ou poucos clones dentro de cada fragmento florestal, podem contribuir para o alto investimento reprodutivo com a subseqüente formação de frutos por autopolinização.

Agradecimentos - Somos gratos a Paulo Eugênio Oliveira pelas sugestões e auxílio nas análises de microscopia de fluorescência; a Leandro Freitas e Tatiana Sendulsky pela leitura crítica do manuscrito; a Vera Lígia L. Machado pela identificação dos himenópteros e a Rubens Rondon pelo auxílio nos trabalhos de campo.

\section{Referências bibliográficas}

BAWA, K.S. 1974. Breeding systems of tree species of a lowland tropical community. Evolution 28:85-92.
BAWA, K.S. \& CRISP, J.E. 1980. Wind-pollination in the understorey of a rain forest in Costa Rica. Journal of Ecology 68:871-876.

BOGDAN, A.V. 1960. Grass pollination by bees in Kenya. Proceedings of the Linnean Society of London 173:57-61.

BULLOCK, S.H. 1985. Breeding systems in the flora of a tropical deciduous forest in Mexico. Biotropica 17:287-301.

CALDERÓN, C.E. \& SODERSTROM, T.R. 1980. The genera of Bambusoideae (Poaceae) of the American continent: keys and comments. Smithsonian Contributions to Botany 44:1-27.

CARVALHO, L.M.T. 1997. Dinâmica de clareiras em uma floresta de nuvem na Serra do Ibitipoca, Minas Gerais. Dissertação de mestrado, Universidade Federal de Lavras, Lavras.

CONNOR, H.E. 1986. Reproductive biology in the grasses. In Grass systematics and evolution (T.R. Soderstrom, K.W. Hilu, C.S. Campbell \& M.E. Barkworth, eds.). Smithsonian Institution Press, Washington, p.117-132.

FAEGRI, K. \& VAN DER PIJL, L. 1979. The principles of pollination ecology. Pergamon Press, New York.

FILGUEIRAS, T.S. 1988. Bambus nativos do Distrito Federal, Brasil (Gramineae: Bambusoideae). Revista Brasileira de Botânica 11:47-66.

FILGUEIRAS, T.S. \& PEREIRA, B.A.S. 1988. On the flowering of Actinocladum verticillatum (Gramineae: Bambusoideae). Biotropica 20:164-166.

FRIAR, E. \& KOCHERT, G. 1994. A study of genetic variation and evolution of Phyllostachys (Bambusoideae: Poaceae) using nuclear restriction fragment lenght polymorphisms. Theoretical \& Applied Genetics 89:265-270.

GIOVANNONI, M., VELLOZO, L.G.C. \& KUBIAK, G.V.L. 1946. Sobre as "ratadas" do primeiro planalto paranaense. Arquivos de Biologia e Tecnologia 1:185-195.

GUILHERME, F.A.G. 1999. Efeitos do regime de inundação e de bambus na dinâmica da comunidade arbórea de um fragmento de floresta semidecídua no sul de Minas Gerais. Dissertação de mestrado, Universidade Federal de Lavras, Lavras.

JANZEN, D.H. 1976. Why bamboos wait so long to flower? Annual Review of Ecology \& Systematics 7:347-391.

KENNARD, W.C. 1955. Flowering of the bamboo Guadua amplexifolia Presl. in Puerto Rico. Lloydia 18:193-196.

LIESE, W. 1987. Research on bamboo. Wood Science \& Technology 21:189-209.

LONDOÑO, X. 1990. Aspectos sobre la distribución y la ecologia de los bambues de Colombia (Poaceae: Bambusoideae). Caldasia 16:139-153.

MARTIN, F.N. 1959. Staining and observing pollen tubes in the style by means of fluorescence. Stain Technology 34:125.

MCCLURE, F.A. 1973. Genera of bamboos native to the new world (Gramineae: Bambusoideae). Smithsonian Contributions to Botany 9:1-148.

NADGAUDA, R.S., PARASHARAMI, V.A. \& MASCARENHAS, A.F. 1990. Precocious flowering and seeding behaviour in tissue-cultured bamboos. Nature 344:335-336

NADGAUDA, R.S., JOHN, C.K. \& MASCARENHAS, A.F. 1993. Floral biology and breeding behavior in the bamboo Dendrocalamus strictus Nees. Tree Physiology 13:401-408. 
OLIVEIRA-FILHO, A.T., VILELA, E.A., GAVILANES, M.L. \& CARVALHO, D.A. 1994. Effect of flooding regime and understorey bamboos on the physiognomy and tree species composition of a tropical semideciduous forest in Southeastern Brazil. Vegetatio 113:99-124.

OLMOS, F. 1996. Satiation or deception?: mast-seeding Chusquea bamboos, birds and rats in the Atlantic Forest. Revista Brasileira de Biologia 56:391-401.

PEREIRA, C. 1941. Sobre as "ratadas" no sul do Brasil e o ciclo vegetativo das taquaras. Arquivos do Instituto de Biologia de São Paulo 12:175-195.

POHL, R.W. 1991. Blooming history of the Costa Rica bamboos. Revista de Biologia Tropical 39:111-124.

RICHARDS, A.J. 1986. Plant breeding systems. George Allen \& Unwin, London.

SENDULSKY, T. 1992. Merostachys burmanii (Poaceae: Bambusoideae: Bambuseae), a new species from Brazil. Novon 2:111-113.

SENDULSKY, T. 1995. Merostachys multiramea (Poaceae: Bambusoideae: Bambuseae) and similar species from Brazil. Novon 5:76-96.

SENDULSKY, T. 1997. Twelve new species of Merostachys (Poaceae: Bambusoideae: Bambuseae) from Brazil. Novon 7:285-307.
SODERSTROM, T.R. 1981. Observations on a fire-adapted bamboo of the Brazilian cerrado, Actinocladum verticillatum (Poaceae: Bambusoideae). American Journal of Botany 68:1200-1211.

SODERSTROM, T.R. \& CALDERÓN, C.E. 1971. Insect pollination in tropical rain forest grasses. Biotropica 3:1-16.

SODERSTROM, T.R. \& CALDERÓN, C.E. 1979. Ecology and phytossociology of bamboo vegetation. In Ecology of grasslands and bamboolands in the world (M. Numata, ed.). Gustav Fischer Verlag, Chiba, p.223-236.

SODERSTROM, T.R., JUDZIEWICZ, E.J. \& CLARK, L.G. 1988. Distribution patterns of neotropical bamboos. In Proceedings of a workshop on neotropical distribution patterns (P.E. Vanzolini \& W.R. Heyer, eds.). Academia Brasileira de Ciências, Rio de Janeiro, p.121-157.

VENKATESH, C.S. 1984. Dichogamy and breeding system in a tropical bamboo Ochlandra travancorica. Biotropica 16:309-312.

WATSON, L. \& DALLWITZ, M.J. 1994. The grass genera of the world. Cambridge University Press, Cambridge.

WHITEHEAD, D.R. 1969. Wind pollination in the angiosperms: evolutionary and environmental considerations. Evolution 23:28-35. 